\title{
Article \\ 3D Bioprinting of Gelatin-Xanthan Gum Composite Hydrogels for Growth of Human Skin Cells
}

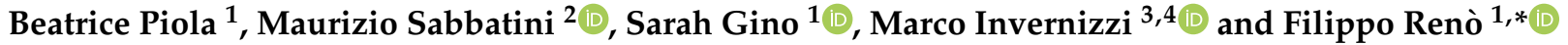 \\ 1 Innovative Research Laboratory for Wound Healing, Health Sciences Department, Medical School, \\ Università del Piemonte Orientale, Via Solaroli 17, 28100 Novara, Italy; 20021634@studenti.uniupo.it (B.P.); \\ sarah.gino@uniupo.it (S.G.) \\ 2 Department of Sciences and Technological Innovation, Università del Piemonte Orientale, Via T. Michel 11, \\ 15121 Alessandria, Italy; maurizio.sabbatini@uniupo.it \\ 3 Health Science Department, Physical Medicine and Rehabilitation Division, \\ Università del Piemonte Orientale, Via Solaroli 17, 28100 Novara, Italy; marco.invernizzi@med.uniupo.it \\ 4 Department of Integrated Research and Innovation, Translational Medicine Unit (DAIRI), \\ Hospital "S.S. Antonio e Biagio e Cesare Arrigo", 15121 Alessandria, Italy \\ * Correspondence: filippo.reno@med.uniupo.it; Tel.: +39-0321660634
}

check for updates

Citation: Piola, B.; Sabbatini, M.; Gino, S.; Invernizzi, M.; Renò, F. 3D Bioprinting of Gelatin-Xanthan Gum Composite Hydrogels for Growth of Human Skin Cells. Int. J. Mol. Sci. 2022, 23, 539. https://doi.org/ 10.3390/ijms23010539

Academic Editor: Yi Cao

Received: 4 November 2021

Accepted: 30 December 2021

Published: 4 January 2022

Publisher's Note: MDPI stays neutral with regard to jurisdictional claims in published maps and institutional affiliations.

Copyright: (C) 2022 by the authors. Licensee MDPI, Basel, Switzerland. This article is an open access article distributed under the terms and conditions of the Creative Commons Attribution (CC BY) license (https:// creativecommons.org/licenses/by/ $4.0 /)$.

\begin{abstract}
In recent years, bioprinting has attracted much attention as a potential tool for generating complex 3D biological constructs capable of mimicking the native tissue microenvironment and promoting physiologically relevant cell-cell and cell-matrix interactions. The aim of the present study was to develop a crosslinked 3D printable hydrogel based on biocompatible natural polymers, gelatin and xanthan gum at different percentages to be used both as a scaffold for cell growth and as a wound dressing. The CellInk Inkredible 3D printer was used for the 3D printing of hydrogels, and a glutaraldehyde solution was tested for the crosslinking process. We were able to obtain two kinds of printable hydrogels with different porosity, swelling and degradation time. Subsequently, the printed hydrogels were characterized from the point of view of biocompatibility. Our results showed that gelatin/xanthan-gum bioprinted hydrogels were biocompatible materials, as they allowed both human keratinocyte and fibroblast in vitro growth for 14 days. These two bioprintable hydrogels could be also used as a helpful dressing material.
\end{abstract}

Keywords: bioprinting; hydrogel; xanthan gum; gelatin; biocompatibility

\section{Introduction}

Hydrogels are crosslinked, insoluble and hydrophilic polymers that are capable of containing a large amount of water thanks to their porosity and three-dimensional network structure [1]. The hydrophilic capacity of hydrogels is due to the presence of hydrophilic groups along the polymer chain, while crosslinks can be built by electrostatic dipole-dipole interactions and covalent bonds [2]. In recent years, hydrogels have aroused a significant interest in biomedical and clinical research due to their capacity to create a favorable microenvironment for cell growth and/or differentiation [3]. Certainly, they have several application domains, such as drug delivery $[4,5]$, tissue engineering $[2,6,7]$, regenerative medicine [8,9] and wound dressings [10-12]. In particular, hybrid composite hydrogels (made by gelatin, xanthan gum, glutaraldehyde and HPLC-grade water) have been shown to exhibit good wound-healing ability [13].

Gelatin (Gel), which is produced by partial hydrolysis of collagen, displays good biocompatibility and biodegradability properties and is commonly used in medical areas, due to its great biological advantages and low cost [14]. Several studies have highlighted the beneficial effects of Gel for migration, adhesion and growth of cells in tissue regeneration processes [14-16]. Moreover, its biodegradability is the result of the presence of matrix metalloproteinase (MMP) cleavage sites, and it is an important characteristic for 
the development of in vivo implanted hydrogels, since scaffold degradation allows for the deposition and production of a new extracellular matrix [17].

Xanthan gum (Xnt) is a microbial-derived high-molecular-weight heteropolysaccharide that is employed in medical field and tissue engineering for its biocompatibility and gelling characteristics [18], as well as being available at a low cost and easy to process [19]. For these important properties, it has been widely used in the pharmaceutic field as a thickener, suspender and emulsifier [20] and also in the manufacture of biodegradable hydrogels for skin scaffold $[18,21]$.

An important limit of gelatin and xanthan-gum hydrogels is their mechanical weakness and dissolution behavior in solvent [17]. It is known that, after immersion in water, they present a severe swelling rate, due to the absorption of the solvent. This is a disadvantage for its employment as wound scaffold, because severe swelling will make the dressings unable to maintain the structure of the dressings and fit the wound [14]. To solve this problem, hydrogels are stabilized by crosslinking to increase their material strength and hydrolysis resistance, and to keep their shape, avoiding swelling phenomena [22]. Through crosslinking, it is possible to stabilize the chemistry of the polymer, extending the chains, with consequent modifications of the network structure [23].

Crosslinking agents can be inserted into hydrogels through different methodologies, such as physical methods and the use of chemicals or enzymes [24]. Among the chemical methods, glutaraldehyde (GTA) $[25,26]$ is one of the most used crosslinking agent in the biomedical sector, despite its cytotoxicity at certain concentrations [25]. Crosslinking of collagen derivatives with GTA includes the production of permanent junctions by reactions between free amine groups of lysine or hydroxylysine amino acid residues in polypeptide chains and aldehyde groups of glutaraldehyde [23,27]. Moreover, GTA is easily available at a low cost, and in aqueous solution, it allows crosslinking to be achieved in a relatively short time [27].

Three-dimensional bioprinting is an early stage technology with important consequences and applications in the biomedical and tissue-engineering fields, as it allows the creation of 3D tissue constructs through programmed models and the distribution of the so-called bio-ink by means of the movement of a motorized stage [28,29]. Bio-inks have different compositions (biomaterials, biomolecules and cell) depending on their use; in fact, properties such as printability, biocompatibility and physical strength could affect the final printed construct [30]. Then, the printed constructs could be crosslinked after bioprinting to stabilize its final shape and structure. This technique allows for the standardization of the bioprinting process, with high reproducibility and precise control, potentially enabling high-throughput production [29]. However, current 3D bio-printing methods still have technical limitations to overcome, such as high-resolution cell deposition and controlled cell distribution [28].

Considering this, the aim of present study was to develop a low-cost crosslinked 3D printable hydrogel based on biocompatible natural polymers (gelatin and xanthan gum) and characterize it as a cell-growth scaffold to use for both in vitro growth of tissues and wound dressing.

\section{Results}

\subsection{Bioprinting and Crosslinking}

As reported in Table 1, different concentrations of Gel/Xnt were tested to achieve maximum printability. In the framework of extrusion bioprinting, hydrogel printability generally refers to the extrudability, filament formation and shape fidelity. By modulating the process and $3 \mathrm{D}$ printer parameters, it was possible to obtain predictable structures, as were designed in the 3D printing software. The Slic3r program was used to modify the code for a tissue model in order to optimize fill pattern, speed, density and extrusion [31]. A 25-gauge $(0.25 \mathrm{~mm}$ aperture) printer tip with pneumatic extrusion pressures below $21 \mathrm{kPa}$ was used. Gelatin $(2.5 \mathrm{w} / \mathrm{v} \%$ and $3 \mathrm{w} / \mathrm{v} \%)$, along with xanthan gum $(1.2 \mathrm{w} / \mathrm{v} \%)$, resulted 
in being printable and showed the best resolution, intended as shape fidelity, using a pressure range of 10 to $20 \mathrm{kPa}$.

Table 1. Hydrogels compositions.

\begin{tabular}{cccc}
\hline \multirow{2}{*}{ Label } & \multicolumn{2}{c}{ Composition (w/vo) } & $\begin{array}{c}\text { Printability } \\
\text { (Qualitative Evaluation) }\end{array}$ \\
\cline { 2 - 3 } & Gelatin (Gel) & Xanthan Gum (Xnt) & - \\
\hline $2.5 \mathrm{Gel} 1$ & 2.5 & 0.7 & + \\
$2.5 \mathrm{Gel} 2$ & $"$ & 1 & ++ \\
$2.5 \mathrm{Gel} 3$ & $"$ & 1.2 & - \\
3Gel1 & 3 & 0.3 & - \\
3Gel2 & $"$ & 0.7 & + \\
3Gel3 & $"$ & 1 & ++ \\
3Gel4 & $"$ & 1.2 & \\
\hline
\end{tabular}

After the printing process, three different concentrations $(0.3,0.5$ and $1 \mathrm{v} / \mathrm{v} \%)$ of glutaraldehyde and two different immersion times ( 1 and $3 \mathrm{~h}$ ) were used for the hydrogel crosslinking test. The higher concentrations of glutaraldehyde, with a longer immersion time, led to greater resistance and permanence of the print shape, which could adversely affect the biodegradability of the printed hydrogels. Therefore, in order to reduce the excessive tribological qualities (durability) [25,32], and also to minimize its possible toxicity $[24,25,32]$, the low concentration of glutaraldehyde was assessed. The 3Gel4 and 2.5Gel3 hydrogels crosslinked with $0.3 \mathrm{v} / \mathrm{v} \%$ GTA for $3 \mathrm{~h}$ resulted in the best stability in PBS and DMEM at $37^{\circ} \mathrm{C}$ (Table 2), maintaining their shape for over $48 \mathrm{~h}$, not disintegrating even after a week of immersion.

Table 2. Different concentrations of glutaraldehyde and crosslinking times for 2.3Gel3 and 3Gel4.

\begin{tabular}{|c|c|c|c|c|c|}
\hline \multirow{2}{*}{ Label } & \multicolumn{2}{|c|}{ Composition (w/v\%) } & \multirow{2}{*}{$\begin{array}{l}\text { GTA Concentration } \\
(\mathbf{v} / \mathbf{v} \%)\end{array}$} & \multirow{2}{*}{ Time (h) } & \multirow{2}{*}{$\begin{array}{c}\text { Stability in } \\
\text { DMEM }\end{array}$} \\
\hline & Gelatin (Gel) & $\begin{array}{l}\text { Xanthan } \\
\text { Gum (Xnt) }\end{array}$ & & & \\
\hline 2.5Gel3 & 2.5 & 1.2 & 0.3 & 1 & - \\
\hline " & 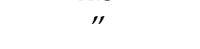 & $\prime$ & $\prime$ & 3 & ++ \\
\hline " & " & " & 0.5 & 1 & - \\
\hline$\prime \prime$ & $\prime \prime$ & $\prime \prime$ & $\prime \prime$ & 3 & - \\
\hline$"$ & $"$ & $"$ & 1 & 1 & - \\
\hline " & " & " & $\prime$ & 3 & - \\
\hline 3Gel4 & 3 & 1.2 & 0.3 & 1 & - \\
\hline$\prime \prime$ & $"$ & $\prime \prime$ & $\prime \prime$ & 3 & ++ \\
\hline$"$ & $"$ & $\prime \prime$ & 0.5 & 1 & - \\
\hline$"$ & $"$ & $\prime$ & $\prime \prime$ & 3 & - \\
\hline$"$ & $"$ & $"$ & 1 & 1 & - \\
\hline$"$ & $"$ & $\prime$ & $"$ & 3 & - \\
\hline
\end{tabular}

\subsection{Characterization of $3 D$-Printed Hydrogel}

\subsubsection{Morphology}

Figure 1 shows the images obtained by the morphological analysis of $1 \mathrm{~cm}^{2}$ square shapes obtained by extrusion bioprinting. A comparison of the different hybrid composites hydrogels showed that both $3 \mathrm{Gel} 4$ crosslinked and non-crosslinked have a defined shape compared to $2.5 \mathrm{Gel} 3$, which appears to be less viscous. These results showed that xanthan gum is a good stabilizing agent, because the hydrogel with $3 \mathrm{w} / \mathrm{v} \%$ of Gel without crosslinker is able to maintain its print shape, which even improves after the immersion in GTA. 


\section{No Crosslinked}

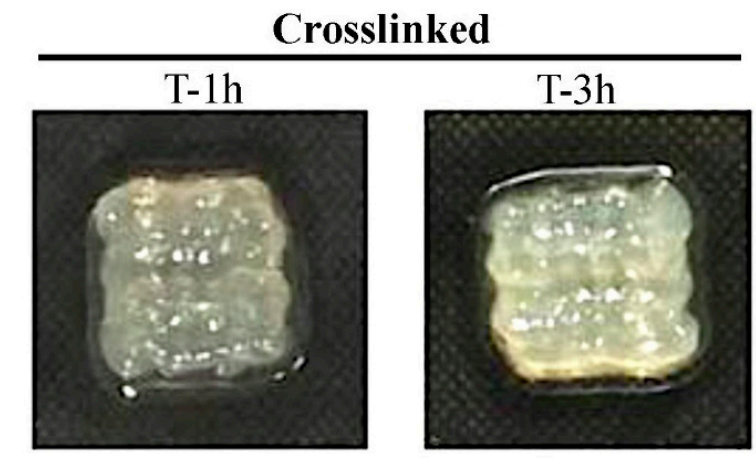

2.5Gel3
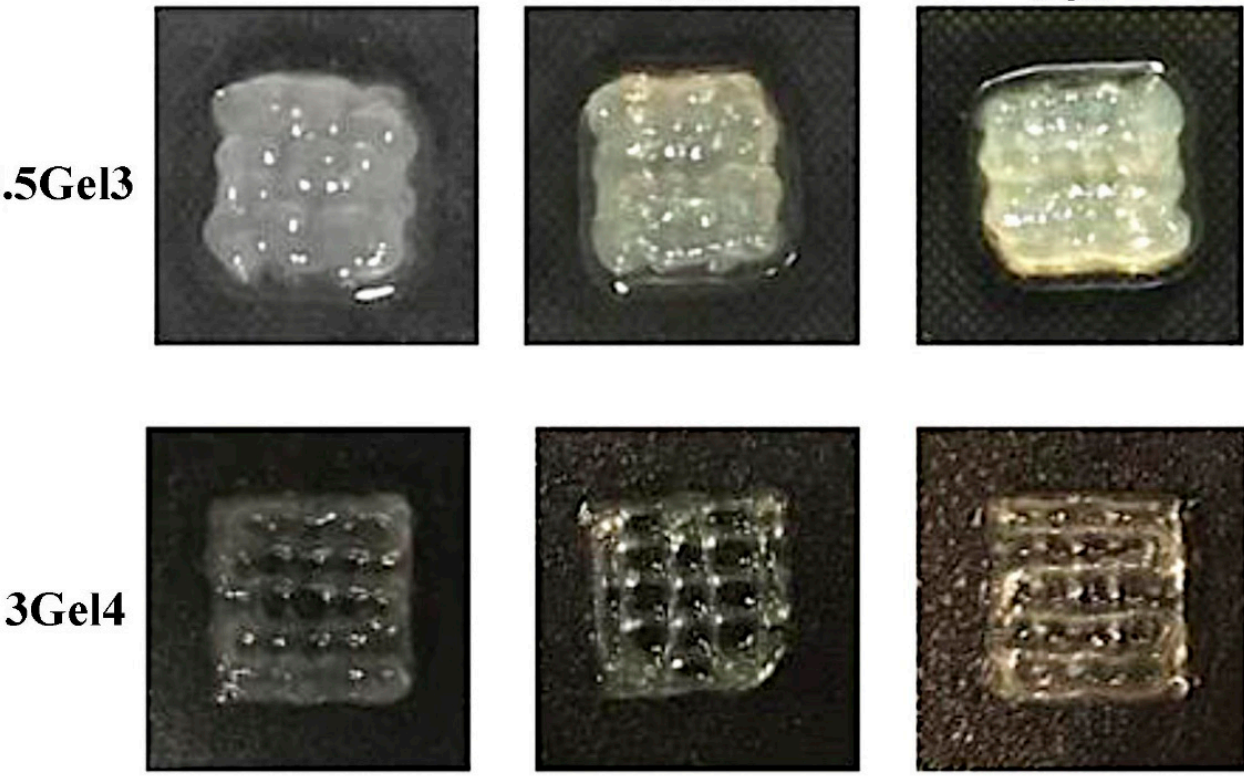

Figure 1. Morphological analysis of the 2.5Gel3 and 3Gel4 hydrogels after printing (not crosslinked) and after submersion for 1 and $3 \mathrm{~h}$ in the $0.3 \mathrm{v} / \mathrm{v} \%$ glutaraldehyde (crosslinked). Hydrogels were printed in a $1 \mathrm{~cm}^{2}$ square shape.

\subsubsection{Moisture}

The evaluation of the water content of a hydrogel is required for many biomedical applications. The percentages of water in the hydrogels were similar to each other, independently from the gelatin content (Figure 2). Moreover, the moisture values for both hydrogels were above $90 \%$, as reported in the literature for other hydrogels [13,32].

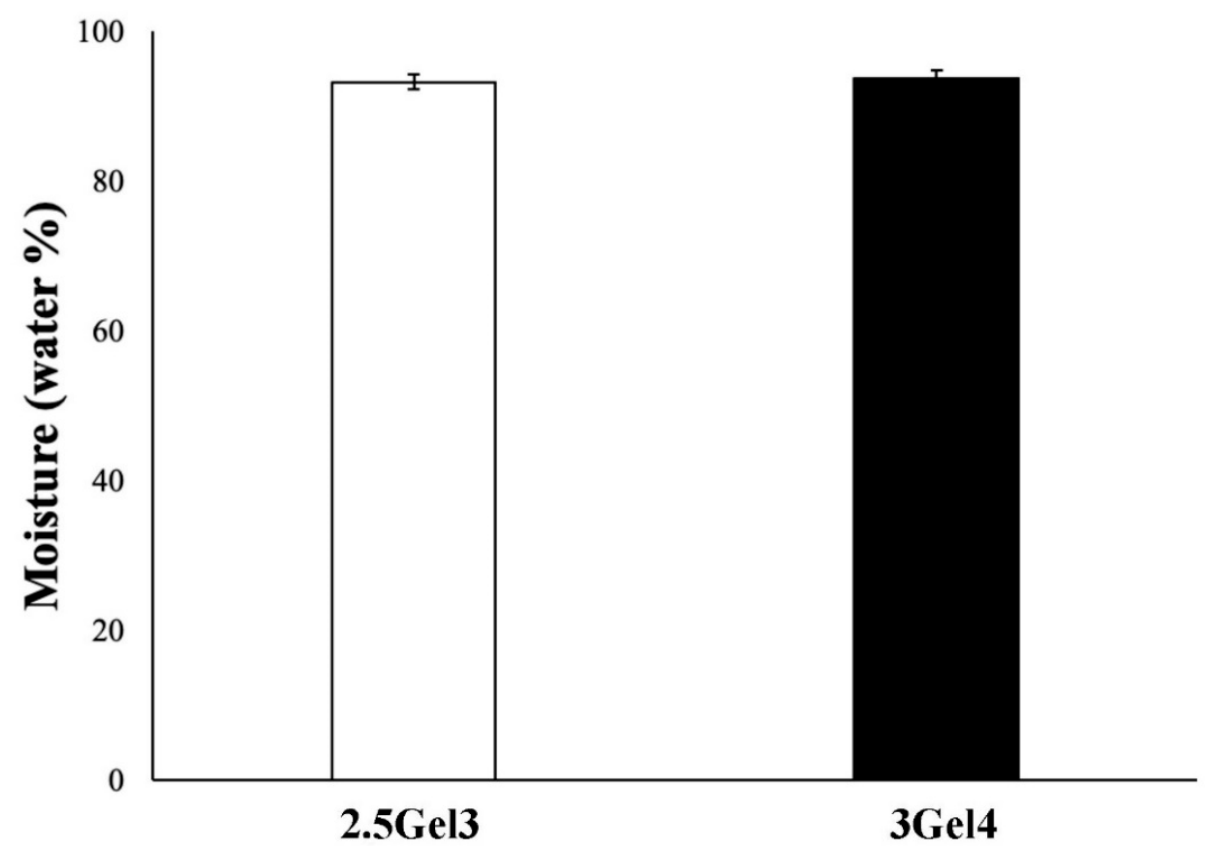

Figure 2. Moisture percentage of 2.5Gel3 and 3Gel4 hybrid composite hydrogels after hydration and drying process at $37^{\circ} \mathrm{C}$ for 2 days. 


\subsubsection{Swelling Test}

The swelling tests were carried out on $2.5 \mathrm{Gel} 3$ and $3 \mathrm{Gel} 4$ printed hydrogels crosslinked and non-crosslinked. These prints containing $2.5 \mathrm{w} / \mathrm{v} \%$ and $3 \mathrm{w} / \mathrm{v} \%$ of gelatin, after one hour of submersion in deionized water, showed a swelling rate of $1110.25 \% \pm 339$ and $423.17 \% \pm 47.34$ respectively ( $p$-value 0.02543 ), increasing after three hours of submersion until the sixth hour, where all the prints resulted in being completely dissolved (Figure $3 \mathrm{a}$ ). On the other hand, crosslinked prints using $0.3 \%$ glutaraldehyde immersion for $3 \mathrm{~h}$ showed more stable and more resistant swelling in deionized water (Figure $3 \mathrm{~b}$ ). The swelling rate of the hydrogel with $2.5 \mathrm{w} / \mathrm{v} \%$ of Gel was of $489.70 \pm 168.57 \%$ compared to $30.27 \pm 7.59 \%$ ( $p$-value 0.009199 ) of $3 \mathrm{w} / \mathrm{v} \%$ Gel content. In Figure $3 \mathrm{~b}$, it is possible to observe that, after $24 \mathrm{~h}$, the $2.5 \mathrm{Gel} 3 \mathrm{had}$ achieved a much higher swelling rate than hydrogel 3Gel4. Furthermore, the different crosslinked hydrogels were observed under the light microscope (Figure 4). The images reported in Figure 4 confirm that the crosslinked prints containing $3 \mathrm{w} / \mathrm{v} \%$ Gel are more resistant to swelling.
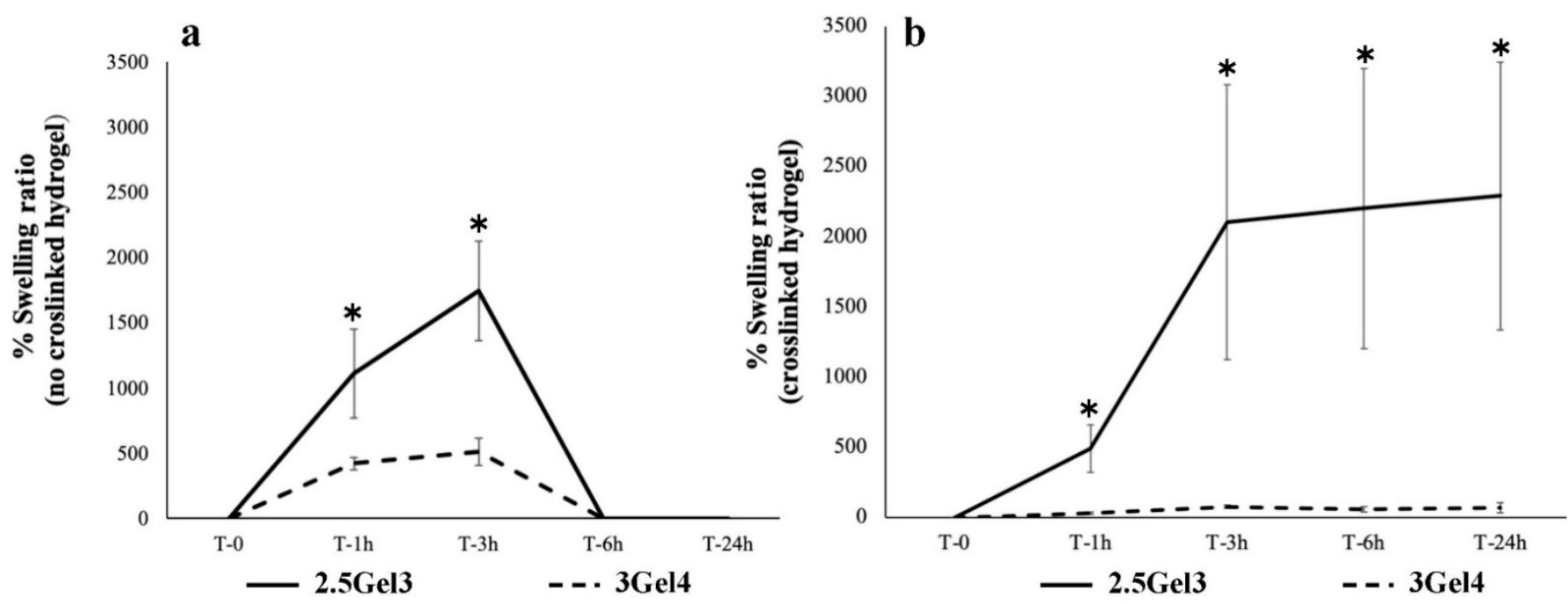

Figure 3. Swelling ratio of rehydrated 2.5Gel3 and 3Gel4 hydrogels by immersing them in deionized water and weighed at different time points, from 0 to $24 \mathrm{~h}$. (a) Swelling rate of non-crosslinked hydrogels and (b) swelling rate of crosslinked; * $p<0.01$.

T-0

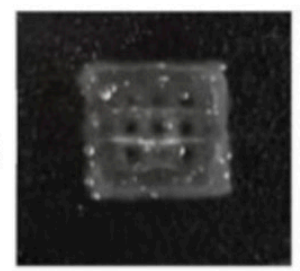

2.5Gel3

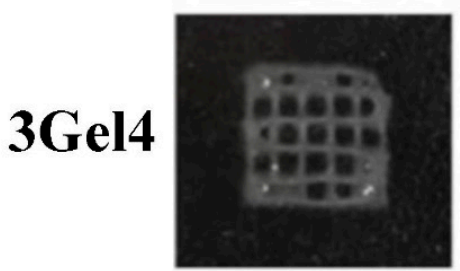

T-1h
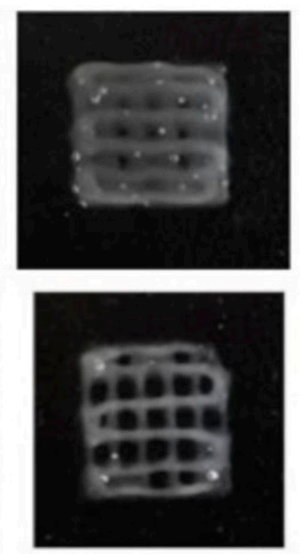

T-3h
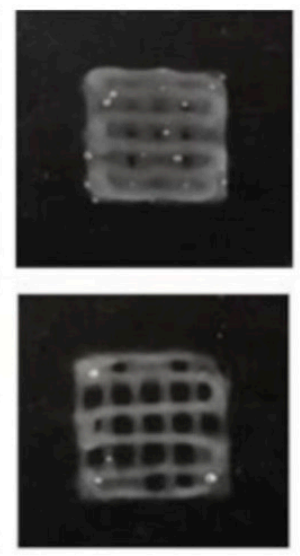

T-6h
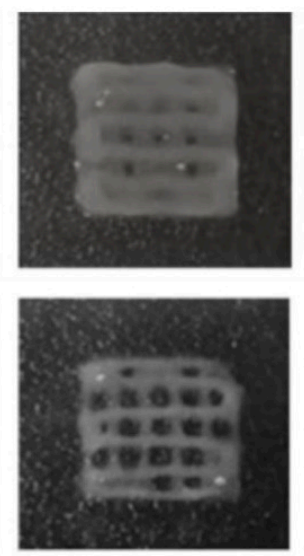

T-24h
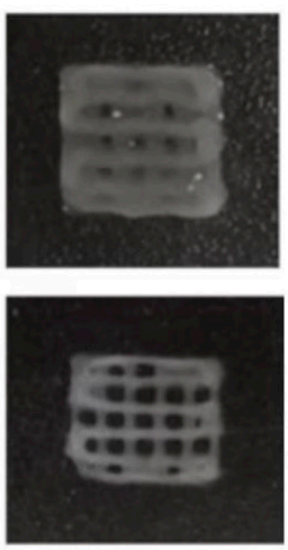

Figure 4. Digital photos of the $2.5 \mathrm{Gel} 3$ and $3 \mathrm{Gel} 4$ hydrogels crosslinked with $0.3 \mathrm{v} / \mathrm{v} \%$ glutaraldehyde during the swelling test at different time points, from 0 to $24 \mathrm{~h}$. 


\subsubsection{Hydrolysis}

Hydrolysis values were obtained after 14 days of the printed hydrogels' submersion, which is probably not enough time to demonstrate the full power of water lysis [24]. Although composed mainly of water, hydrogels may undergo degradation by water, as warm temperatures and prolonged periods of time can allow water molecules to interact with the hydrogel. The hydrolysis test was not performed on non-crosslinked prints, as the high solubility of gelatin in warm water causes rapid disintegration. However, the analysis of the crosslinked prints showed initial degradation for the 3Gel4 hydrogel after 10 days with a percentage of hydrolysis of $53.96 \pm 18.01 \%$ ( $p$-value 0.007441$)$ and after 14 days of $24.41 \pm 28.16 \%(p=0.005756)$ in water at $37{ }^{\circ} \mathrm{C}$ (Figure 5), while crosslinked $2.5 \mathrm{w} / \mathrm{v} \%$ gelatin hydrogel did not lose mass in warm water.

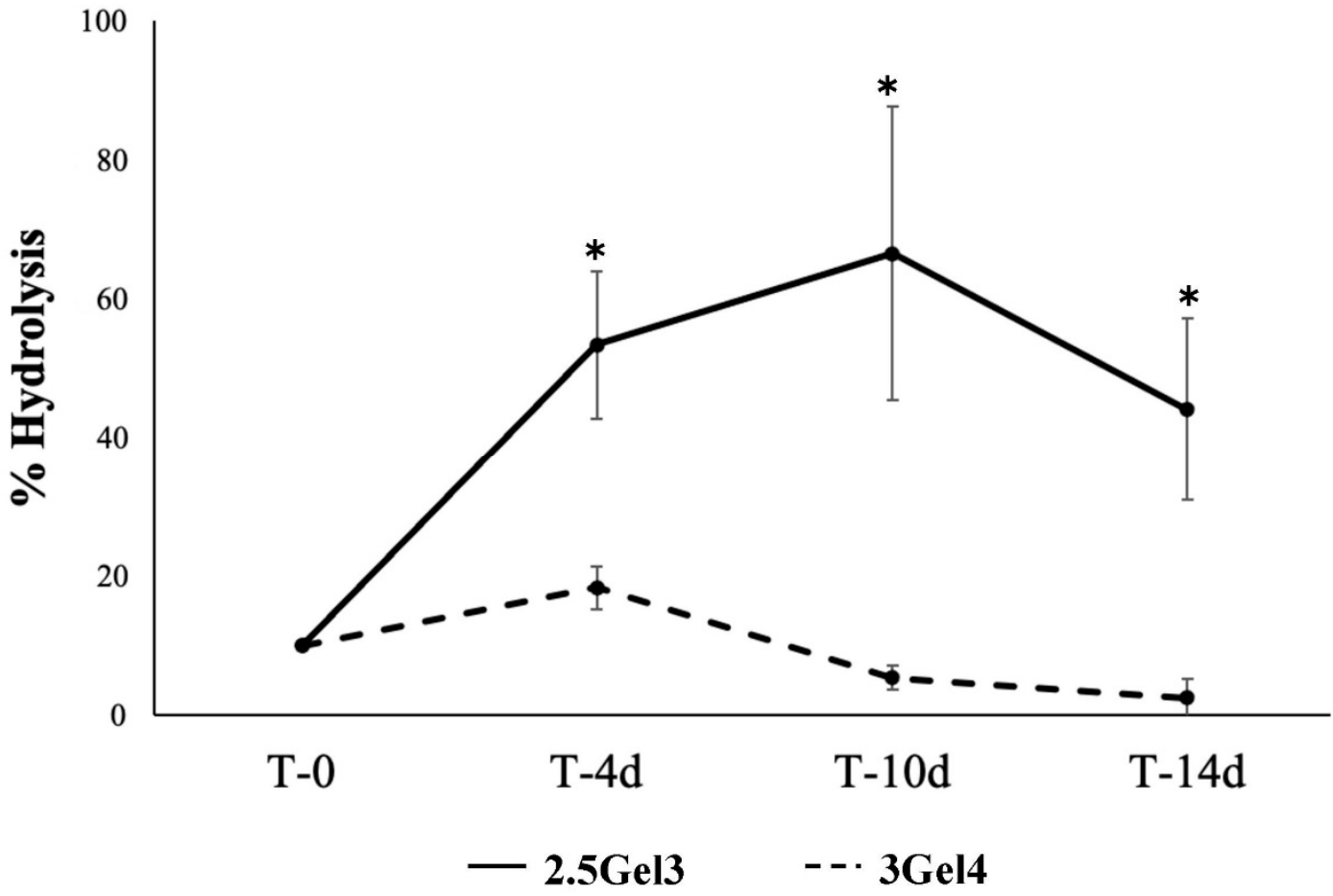

Figure 5. Hydrolysis percentage of the $2.5 \mathrm{Gel} 3$ and $3 \mathrm{Gel} 4$ after soaking in deionized water at $37^{\circ} \mathrm{C}$ from 4 to 14 days; ${ }^{*} p<0.01$.

\subsubsection{Porosity}

An initial porosity analysis, using the liquid displacement method (Figure 6), showed that the hydrogel containing $3 \mathrm{w} / \mathrm{v} \%$ gelatin had a porosity of $30.82 \pm 4.93 \%$, while the $2.5 \mathrm{w} / \mathrm{v} \%$ gelatin hydrogel showed a porosity value of $64.04 \pm 16.68 \%(p=0.02974)$. These results were compared with those obtained by morphological analysis of both hydrogels (Figure 7). Microscope images showed that the pore size in the 2.5Gel3 was greater than that observed in 3Gel4 (Figure 7b). Therefore, the morphological analysis does not confirm the results obtained by the liquid displacement method (Figure 6), thus suggesting that the $2.5 \mathrm{w} / \mathrm{v} \%$ Gel appeared more porous, as the amount of ethanol embedded was high because of the larger pore size than in 3Gel4 (Figure $7 \mathrm{~b}$ ). Moreover, the number of pores within a hydrogel is an important feature for cell encapsulation (Figure 7c). Finally, the morphological analysis showed that the 3Gel4-printed hydrogel had a larger number of pores with a smaller size compared to that of $2.5 \mathrm{Gel} 3$, indicating that it could be used for cell encapsulation. 


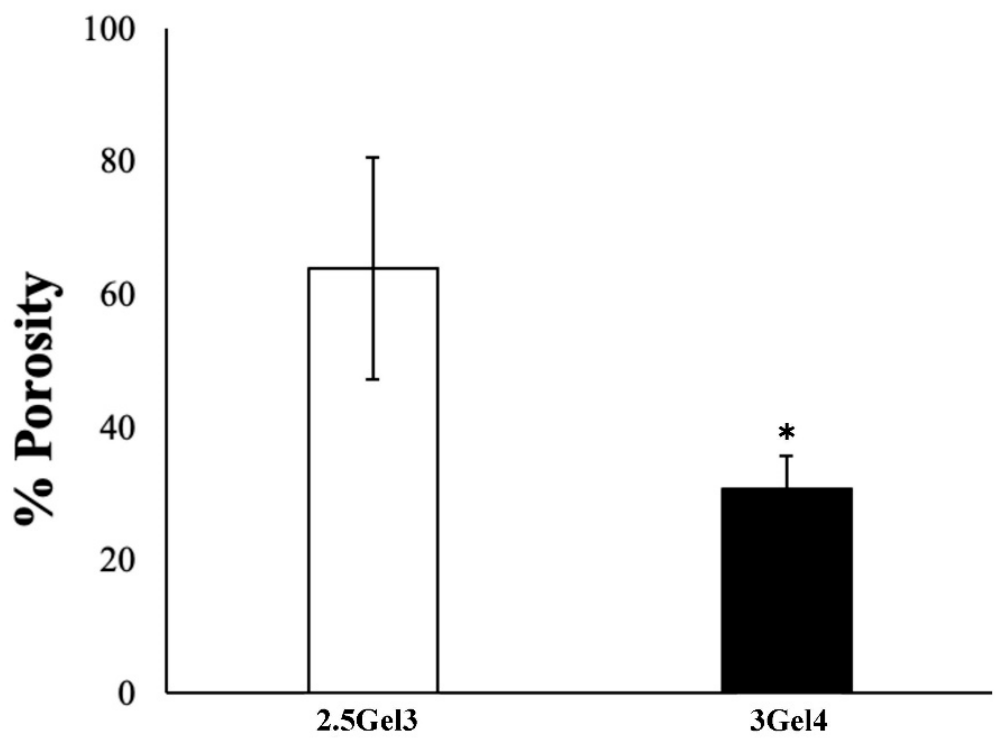

Figure 6. Porosity analysis of the 2.5Gel3 and 3Gel4 hydrogels carried out by liquid displacement method; ${ }^{*} p<0.01$.

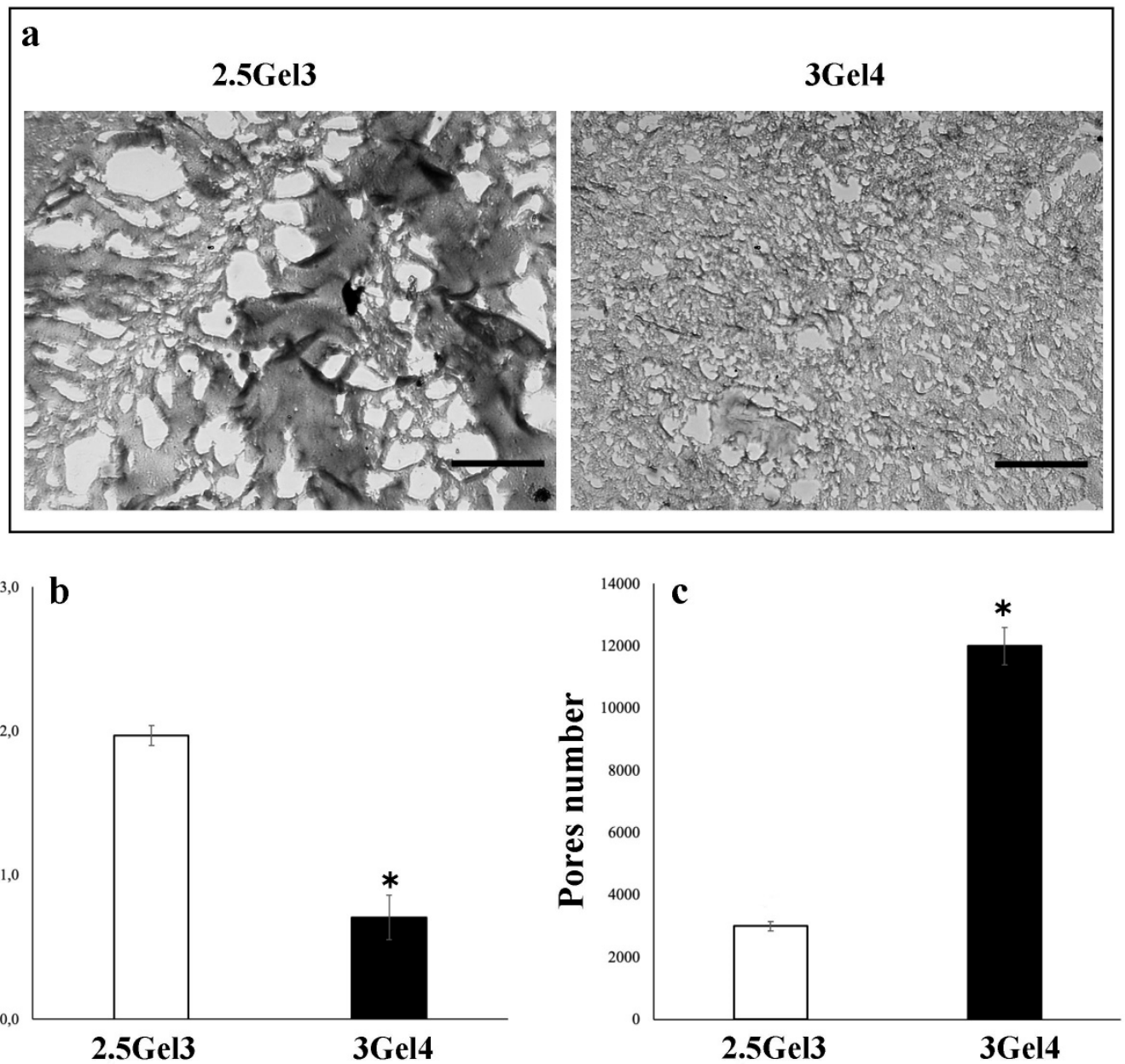

Figure 7. (a) Optical microscope representative images of the 2.5Gel3 and 3Gel4 hydrogels for the pores' morphological analysis. Image area $=25 \mu \mathrm{m}^{2}$, scale bar $1 \mu \mathrm{m} ;(\mathbf{b})$ average pore size $(\mu \mathrm{m})$ of the $2.5 \mathrm{Gel} 3$ and $3 \mathrm{Gel} 4$ hydrogels and (c) average pores number, as analyzed by ImageJ software; $* p<0.01$. 


\subsubsection{Enzymatic Degradation}

Collagenase I is a common mammalian enzyme which is often used at a concentration of $0.1 \%$ in cell analyses, including protein digestion and tissues separation [24]. Collagenase I was used for the enzymatic degradation test, and the data obtained suggested that degradation occurs after an initial period of partial swelling (after $1 \mathrm{~h}$ ), followed by slow and steady degradation (Figure 8a). After $2 \mathrm{~h}$, the residual mass of the 2.5Gel3-printed hydrogel was $93.47 \pm 6.21 \%$, while the $3 \mathrm{Gel} 4$ hydrogel's residual mass was $85.90 \pm 19.43 \%$. The degradation continued slowly over time, with no significant differences between the degradation rate of the $3 \mathrm{Gel} 4$ and 2.5Gel3 hydrogel (Figure $8 \mathrm{~b}$ ).
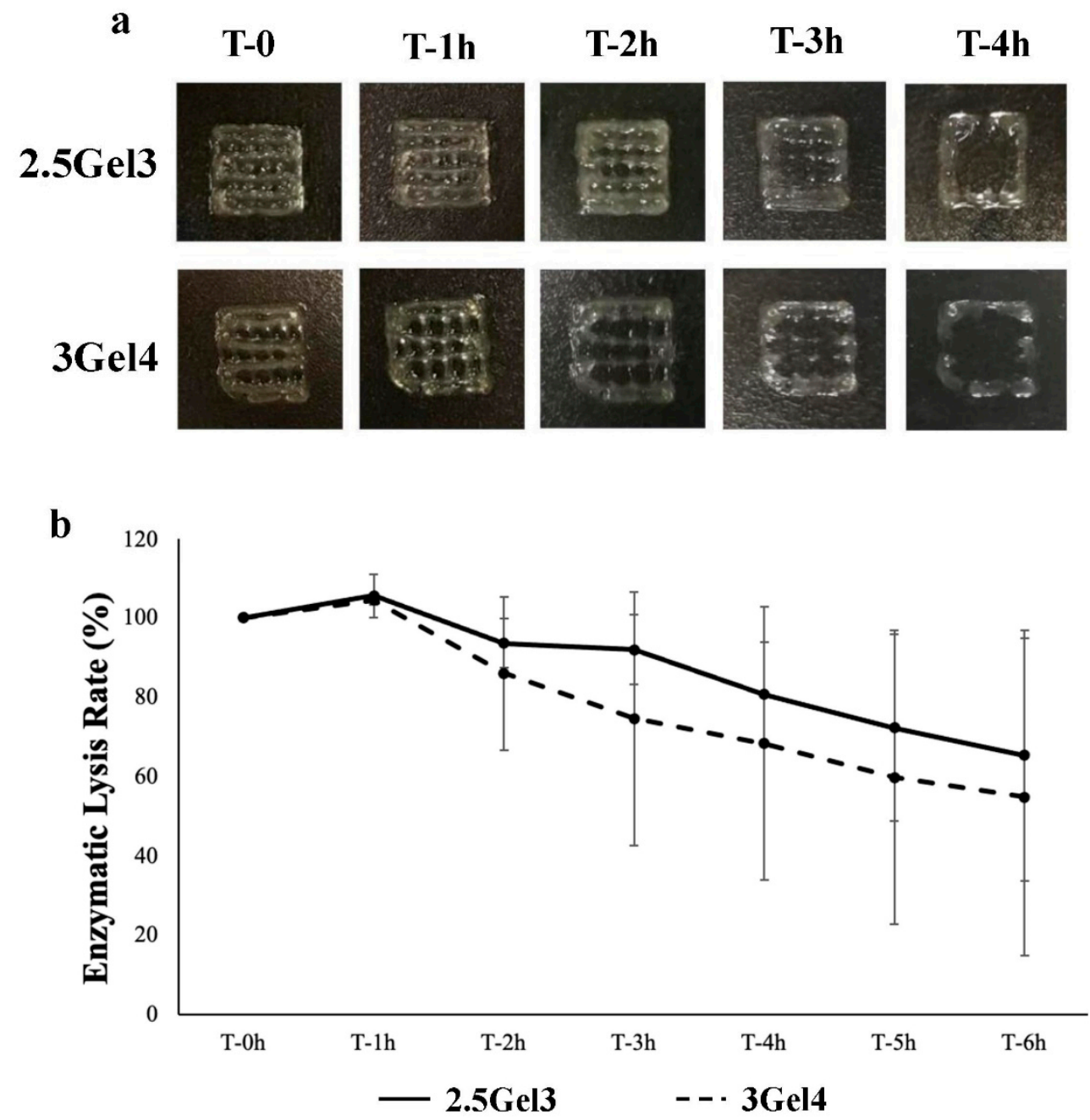

Figure 8. (a) Digital photos of enzymatic degradation analysis of the 2.5Gel3 and 3Gel4 hydrogels with collagenase I from 0 to $4 \mathrm{~h}$; (b) enzymatic lysis rate of the 2.5Gel3 and 3Gel4 hydrogels at different time points, from 0 to $6 \mathrm{~h}$.

\subsubsection{Cell Culture}

Figure 9a shows images of a skin-like structure that was obtained by printing 3Gel4 loaded with human keratinocytes to mimic epidermal layer (upper part) and 2.5Gel3 loaded with human fibroblast to mimic dermal layer (lower part). As shown in the images obtained on day 1 after printing (T1), the cells displayed no signs of cell death, and, as indicated in Figure 9, they increased their number after 7 (T7) and 14 (T14) days both in 3Gel4 and 2.5Gel3. 
a
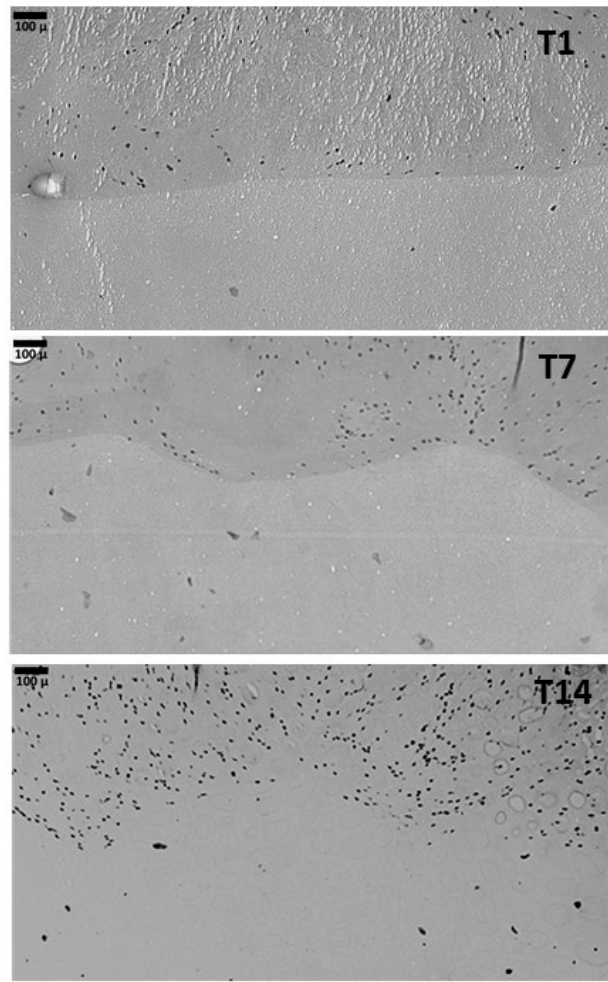

b

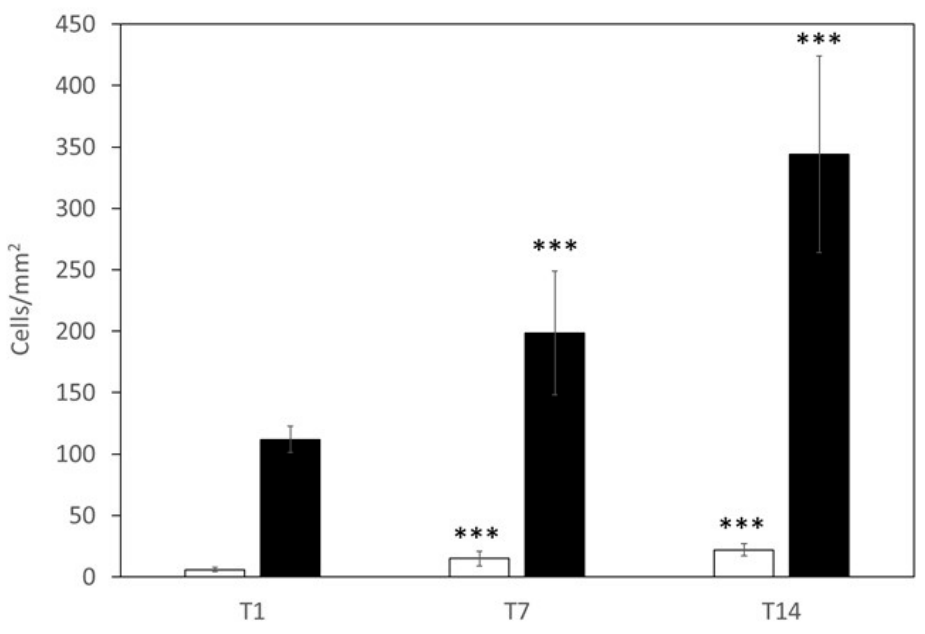

Figure 9. (a) Images obtained by Pannoramic Midi microscope slide digitizer of skin-like model with cell laden 3Gel4 (upper part) and 2.5Gel3 (lower part) after 1 (T1), 7 (T7) and 14 (T14) incubation days. Scale bar $=100 \mu \mathrm{m}$. (b) Bar-graph showing cell numbers scored in 2.5Gel3 (white bar) and 3Gel4 (black bar) at different time points; ${ }^{* * *} p<0.001$ compared to T1.

\section{Discussion}

Three-dimensional bioprinting has drown a lot of attention in the field of modern medicine for tissue engineering and wound healing. Currently, most in vitro studies have been performed on 2D or 3D cell-culture models that are devoid of the structural complexity and function of the native tissues that can be produce by using bioprinting. In fact, bioprinting offers a potential route to generate complex 3D biological constructs that are capable of mimicking the microenvironment of the native tissue and promoting physiologically relevant cell-cell and cell-matrix interactions.

Shawan et al. [13] described the synthesis of Gel/Xnt hydrogels by using $3 \mathrm{w} / \mathrm{v} \%$ or $5 \mathrm{w} / \mathrm{v} \%$ of gelatin and $0.6 \mathrm{w} / \mathrm{v} \%$ xanthan gum and glutaraldehyde $(0.5 \mathrm{v} / \mathrm{v} \%)$ used as crosslinker, and they tested Gel/Xnt hybrid composite hydrogels in experimental skin burn wounds in rats as effective wound-dressing materials. However, the bioprintability properties of the obtained hybrid composite hydrogels were not evaluated. In fact, the original hydrogel could not be 3D-printed, possibly due to the low concentration of the Xnt resulting in low viscosity.

Therefore, to increase the viscosity of the new Gel/Xnt hydrogels (Table 1), the evaporation of the solution was gradually induced, instead of adding water during the synthesis, as reported by Shawan et al. [13], as well as lowering the processing temperature (from $85^{\circ} \mathrm{C}$ to $\left.60-70{ }^{\circ} \mathrm{C}\right)$. Furthermore, the print stability was achieved by adding glutaraldehyde after printing.

Gelatin is widely used in wound-healing applications [33-36], but one of the limitations is its liquification at the normal temperature $\left(37^{\circ} \mathrm{C}\right)$ for the human body [31]. To overcome this drawback, it is possible to use stabilizers, thickeners and crosslinkers, as well as xanthan gum. This is a stabilizer and a homogenizing agent [37], which, being a powder, also influences the viscosity of the hydrogel, extending the surface area and contact points for the adhesion of water molecules within the hydrated matrix. Thus, when 
lower amounts of xanthan gum or gelatin were used in hydrogels (Table 1), a decrease in print-shape retention was observed. On the contrary, higher amounts of gelatin and xanthan gum provided a higher shape retention, but, in addition to xanthan gum, glutaraldehyde is also needed for the gelatin crosslinking process and to maintain the print shape (Table 2). Morphologic analysis demonstrated that the amount of the xanthan gum as glutaraldehyde is important for the stabilization of the hybrid composite hydrogel. Lii et al. [38] reported that Xnt and Gel interact by hydrogen-bonding, involving the $-\mathrm{OH}$ groups and $-\mathrm{NH}_{2}$ groups of xanthan gum and gelatin, respectively, forming many bridges to which water molecules can adhere within the matrix, thus increasing the contact surface for water. In this regard, probably the concentration of $1.2 \mathrm{w} / \mathrm{v} \%$ Xnt is higher than that of a low amount of gelatin $(2.5 \mathrm{w} / \mathrm{v} \%)$. A greater number of bonds between hydroxyl groups of the excess xanthan gum, not linked to gelatin, and water molecules cause an increase of hydration during the synthesis of the hydrogel, and therefore a lower viscosity.

Furthermore, observing the images obtained under the microscope and shown in Figure 1, we see that the non-crosslinked and crosslinked prints with glutaraldehyde respectively showed a color change from white to pale yellow, as is typically associated with the crosslinking reaction $[39,40]$.

The human body is known to be largely composed of water. The main goal of this work is the 3D printing of the cell-seeded hydrogel during therapies such as skin grafts [41] to repair one or more layer of tissue [42] or to accelerate the wound healing. In particular, hydrogel-like materials used for wound healing should have a high percentage of water, because it could improve the interaction between cells and diffusion of molecules [13] without dehydration of the tissues. In both hydrogels, $2.5 \mathrm{Gel} 3$ and $3 \mathrm{Gel} 4$, the percentage of water is around $90 \%$, suggesting that these materials could be used in biomedical applications.

Furthermore, swelling is also an important property to evaluate. Swelling is the ability of a hydrogel to absorb water, gaining weight and volume [25]. Hydrogels with higher swelling values are more likely to change shape and break in hydrated environments. The results of the hydrogels swelling rate may depend on the concentration of gelatin and the presence of glutaraldehyde in their composition. The crosslinking of gelatin is due to the reaction of the aldehyde functional groups present in the glutaraldehyde molecule with free non-protonated $\varepsilon$-amino groups $\left(-\mathrm{NH}_{2}\right)$ of lysine or hydroxylysine belonging to the gelatin. This leads to the formation of amide linkages $[43,44]$. The linkages between the crosslinker and the hydrogel matrix during the crosslinking reactions affect the water-retention ability of the hydrogel [25]. This process can be observed with 3 w/v\% Gel. Probably, since the functional groups of the gelatin are involved in the bonds with all aldehyde groups of the crosslinker, the latter cannot be involved in the bonds with the water molecules, thus positively influencing the swelling rate. On the other hand, when the $2.5 \mathrm{w} / \mathrm{v} \%$ of Gel and $0.3 \mathrm{v} / \mathrm{v} \%$ of GTA were used, the number of functional groups of Gel was not enough to bind all the aldehyde groups of the crosslinker, thus allowing a higher swelling. Comparing the swelling and hydrolysis results, we see that the crosslinked $3 \mathrm{w} / \mathrm{v} \%$ gelatin hydrogel was resistant to swelling but sensible to the hydrolysis process. This could be due to a strong crosslinking of the $3 \mathrm{Gel} 4$ hydrogel with $0.3 \mathrm{v} / \mathrm{v} \%$ GTA. For this reason, many aldehyde groups are linked to gelatin through an amide, bond and, therefore, they are less stable and more subject to the hydrolysis reaction compared to $2.5 \mathrm{Gel} 3$, thus allowing for a greater hydrogel degradation at high temperature by solvation and rapid disintegration of the gelatin $[39,45]$.

The size and number of pores, their connectivity and geometry are the main characteristics for the use of the hydrogels in biomedical applications. Indeed, the ability of cells to proliferate into a 3D structure is affected by the size of the pores, as well as is the biodegradability of the structure itself [46]. In particular, to allow for vascularization and tissue formation, pore sizes should be less than $500 \mu \mathrm{m}$, as larger pore sizes could decrease cell-cell interaction and, thus, their proliferation [46,47]. The $3 \mathrm{Gel} 4$ has a greater number of smaller pores, probably due to the strong bond with the crosslinker that makes this material denser and, therefore, gives it a better porosity compared to 2.5Gel3. 
The results of the enzymatic degradation and hydrolysis test showed the biodegradability of the produced hydrogel. Although crosslinked gelatin hydrogels are soft materials, they are capable of causing irritation and reactions [24]. For this reason, the synthesized Gel/Xnt hydrogel does not need to be highly resistant to degradation, thus allowing host cells to gradually replace the hydrogel in wound healing and absorbing it completely.

Finally, human fibroblast and keratinocytes were mixed with 2.5Gel3 and 3Gel4 hydrogels respectively, and a skin-like structure was printed to evaluate the biocompatibility of both materials. The images of the cell distribution and proliferation in the hydrogels collected after 1, 7 and 14 days in culture showed a good proliferation. These results are also due to the presence of numerous and small pores that induce greater cell proliferation in a 3D structure [46] and to the good biodegradability of the material composing the hydrogels.

\section{Materials and Methods}

\subsection{Hydrogel Preparation}

Shawan et al. [13] reported the preparation of the hydrogels by using different formulations of gelatin (Gel), namely $3 \mathrm{w} / \mathrm{v} \%$ and $5 \mathrm{w} / \mathrm{v} \%$, and $0.6 \mathrm{w} / \mathrm{v} \%$ of xanthan gum (Xnt) for heal ulcers. Based on this work, new compositions of Gel/Xnt hybrid composite hydrogels were designed, modifying the ratio between two components to obtain the best printable hydrogel. Bovine gelatin (Gel) (Sigma-Aldrich, St. Louis, MO, USA) was slowly added to deionized water at $70{ }^{\circ} \mathrm{C}$, under magnetic stirring to avoid the formation of clumps. Afterward, xanthan gum (Xnt) (Sigma-Aldrich, St. Louis, MO, USA) was added into the gelatin solution, and the temperature was maintained between 60 and $70{ }^{\circ} \mathrm{C}$ until water evaporation. Hydrogel was then stored at $4{ }^{\circ} \mathrm{C}$ until use. The formulations used to produce the different hydrogels are reported in Table 1.

\subsection{Bioprinting}

\section{Hydrogel Bioprinting}

CellInk Inkredible 3D printer (CellInk Inkredible 3-D printer, CellInk, Gothenburg, Sweden) was used for the hydrogel printing. Hydrogels were printed to obtain $1 \mathrm{~cm}^{2}$ squares. After preparation, hydrogels were left at $4{ }^{\circ} \mathrm{C}$ from 3 to 10 days, and they were warmed to room temperature before printing. Bio-ink syringes $(3 \mathrm{~mL})$ were filled with the different hydrogels and then loaded into the 3D printer. Printability trials were run at different pressures (from 10 to $20 \mathrm{kPa}$ ), as reported in Table 1.

\subsection{Hydrogel Crosslinking}

Crosslinking trials were performed by using different concentrations of glutaraldehyde (GTA, 0.3, 0.5 and $1 \mathrm{v} / \mathrm{v} \%$,) obtained from a $25 \mathrm{v} / \mathrm{v} \%$ stock solution. In addition, for each concentration, different submersion times in the glutaraldehyde solution ( 1 or $3 \mathrm{~h}$ ) were tested. The crosslinking of a hydrogel structure occurs in the post-printing process. Crosslinked hydrogels were added to cell culture Dulbecco's Modified Eagle's medium (DMEM) to test their stability (Table 2).

\subsection{Characterization of 3D-Printed Hydrogel}

\subsubsection{Morphology}

The macroscopic morphology of the hydrogel was observed by taking several photos, using a high-resolution digital camera (NIKON D5600). Optimal cutting temperature compound (OCT compound) was used to incorporate the hydrogels prior to frozen sectioning on a microtome cryostat, obtaining hydrogel micron slices. The optical reverse microscope (Motic AE2000, Motic Europe, Barcelona, Spain) was used to evaluate the microscopic morphology of the different printed hydrogels, both crosslinked and non-crosslinked. 


\subsubsection{Moisture}

The moisture percentage was measured as described by Shawan et al. [13]. On day 3 of stabilization, hydrated prints were weighted $\left(\mathrm{W}^{\mathrm{H}}\right)$, stored at $37^{\circ} \mathrm{C}$ for 2 days to allow the drying process to be completed and then weighed again $\left(\mathrm{W}^{\mathrm{D}}\right)$. The percentage of moisture (water) in a printed hydrogel was calculated as follows (Equation (1)):

$$
\text { Moisture }(\%)=\left[\left(\mathrm{W}^{\mathrm{H}}-\mathrm{W}^{\mathrm{D}}\right) / \mathrm{W}^{\mathrm{H}}\right] \times 100
$$

where $\mathrm{W}^{\mathrm{H}}$ is original weight of the sample before drying, and $\mathrm{W}^{\mathrm{D}}$ is weight of the sample after drying. All the experiments were replicated three times, with at least three samples for each condition.

\subsubsection{Swelling Test}

Printed hydrogel, both non-crosslinked and crosslinked, were dried at $37^{\circ} \mathrm{C}$ for $48 \mathrm{~h}$ to perform the swelling test [25]. Dried printed hydrogels were weighed, rehydrated by soaking in deionized water and weighed again after the water was removed, at different time points (time $0,1,3,6$ and $24 \mathrm{~h}$ ). The residual water was eliminated, using filter paper, by capillary action. The swelling ratio (S) [25] was calculated by using the following equation (Equation (2)):

$$
\mathrm{S}=\left[\left(\mathrm{W}^{\mathrm{H}}-\mathrm{W}^{\mathrm{D}}\right) / \mathrm{W}^{\mathrm{D}}\right] \times 100 .
$$

where $\mathrm{W}^{\mathrm{H}}$ is sample hydrated weight, and $\mathrm{W}^{\mathrm{D}}$ is initial dehydrated weight.

All the experiments were replicated three times, with at least three samples for each condition.

\subsubsection{Hydrolysis}

In order to evaluate the hydrolysis, crosslinked printed hydrogels were weighed (time 0 ) and immersed in deionized water at $37^{\circ} \mathrm{C}$. After the time point from 4 to 14 days, the weight of the crosslinked prints was taken by removing the deionized water and lightly dabbing the crosslinked prints with filter paper. The percentage of hydrolysis was obtained by using the following equation (Equation (3)):

$$
\text { Hydrolysis }(\%)=\left[\left(\mathrm{W}^{\mathrm{I}}-\mathrm{W}^{\mathrm{F}}\right) / \mathrm{W}^{\mathrm{I}}\right] \times 100
$$

where $\mathrm{W}^{\mathrm{I}}$ is the before soaking weight, and $\mathrm{W}^{\mathrm{F}}$ is the remaining weight after soaking and removing of the deionized water. All the experiments were replicated three times, with at least three samples for each condition.

\subsubsection{Porosity}

The porosity of the printed hydrogels was evaluated by using the liquid displacement method [24]. Absolute ethanol, which causes neither swelling nor shrinking of gelatin [24], was used for prints' submersion. After 5 min of submersion in a known quantity of absolute ethanol, samples were weighed. The porosity of the hydrogel was calculated as follows (Equation (4)):

$$
\text { Porosity }(\%)=\left[\left(\mathrm{W}_{1}-\mathrm{W}_{3}\right) /\left(\mathrm{W}_{2}-\mathrm{W}_{3}\right)\right] \times 100
$$

where $\mathrm{W}_{1}$ is the initial weight of pure ethanol, $\mathrm{W}_{2}$ is the total weight that combines the weight of the hydrogel with the weight of the ethanol and $W_{3}$ is the ending weight of ethanol without hydrogel [24].

Furthermore, Greyscale 8-bit TIFF images of the 2.5Gel3 and 3Gel4 were processed by using ImageJ software. The ImageJ "particle analysis" function was then used to calculate the size and the numerosity of hydrogel pores. All the experiments were replicated three times, with at least three samples for each condition. 


\subsubsection{Enzymatic Degradation}

The biological stability of the hydrogels was evaluated by exposing them to $0.1 \%$ collagenase type IA (>125 CDU/mg, Sigma-Aldrich, St. Louis, MO, USA) to assess degradation rates [24]. Printed hydrogels were dried at $37^{\circ} \mathrm{C}$ for two days, and before the analysis, the dry prints were soaked in PBS for $1 \mathrm{~h}$, and then they were exposed to the enzymatic solution (prepared in PBS 1X) at $0.1 \%$ collagenase type I for $6 \mathrm{~h}$. Enzymatic degradation tests [24] were performed at $37^{\circ} \mathrm{C}$ in a horizontal shaker. After different time points $(1,2,3$, 4,5 and $6 \mathrm{~h}$ ), the excess water was removed from the printed hydrogels and then weighed. The biomaterial degradation was determined by calculating the percentage of remaining weight versus the original weight. All the experiments were replicated three times, with at least three samples for each condition.

\subsection{Cell Culture}

Primary human-derived-skin fibroblasts and human keratnocytes spontaneously immortalized (HaCaTs) were used for testing printable hydrogels biocompatibility. HaCaTs were purchased from Cell Lines Service GmbH (Eppelheim, Germany), while human fibroblasts were a kind gift from Professor Marco De Andrea (University of Turin, Turin, Italy). Both cell types were grown in culture flask in Dulbecco's modified Eagle's medium (DMEM) containing high glucose levels supplemented with $10 \%$ heat-inactivated fetal bovine serum (FBS) and 1\% Penicillin-Streptomycin (all from Immunological Science, Rome, Italy) in a humidified atmosphere containing $5 \% \mathrm{CO}_{2}$ at $37{ }^{\circ} \mathrm{C}$. Two different cell populations (keratinocytes and fibroblasts) inserted into the two hydrogels of different porosity were used for printing a simple 3D skin-like model with a surface layer that mimics the epidermis (high cell concentration for the epithelium) and a lower layer that mimics the dermis (low cellular concentration for the connective). The 2.5Gel3 and 3Gel4 printable hydrogels were gently mixed with $0.5 \times 10^{6}$ fibroblasts $/ \mathrm{mL}$ and $5 \times 10^{6} \mathrm{HaCaT}$ cells $/ \mathrm{mL}$, respectively, using two syringes connected under a sterile cap. Small cylinders $(0.5 \mathrm{~cm}$ high, $1 \mathrm{~cm}$ wide) were printed by using cell-laden $2.5 \mathrm{Gel} 3$ for the lower layers and 3Gel4 for the upper layers. The cylinders were crosslinked by using GTA as previously indicated. The cell-laden cylinders were washed three times with sterile PBS and incubated for 1, 7 and 14 days in DMEM $10 \%$ FBS at $37^{\circ} \mathrm{C}$ in a $5 \% \mathrm{CO}_{2}$ atmosphere. At the end of the incubation time, the culture medium was removed, and the hydrogels containing the cells were washed with phosphate buffered saline (PBS) 3 times, formalin fixed and paraffin embedded. Samples were then cut in $5 \mu$ slices and stained with hematoxylin/eosin; the cells grown in hydrogels were observed by using a digitizer Pannoramic Midi for microscope slides (Epredia, Palermo, Italy), and their number was evaluated by using the ImageJ software. All the experiments were replicated three times, with at least three samples for each condition.

\subsection{Statistical Analysis}

Data were presented as mean \pm standard deviation (SD). Statistical analyses were performed by using GraphPad PRISM software. Kolmogorov-Smirnoff test was applied to verify the normal distribution of data. One-way ANOVA was employed for multiple comparison, the whereas t-test was used when a comparison between two group occurred. The $p$-values $<0.05$ were considered statistically significant.

\section{Conclusions}

The hybrid composite hydrogels containing different percentages of gelatin and the same amount of xanthan gum were designed to obtain printable materials for in vitro and in vivo biomedical applications. Among all the hydrogel formulations modulating the process and the parameters of the 3D printer, the $2.5 \mathrm{w} / \mathrm{v} \%$ and $3 \mathrm{w} / \mathrm{v} \%$ of gelatin with $1.2 \mathrm{w} / \mathrm{v} \%$ xanthan gum resulted in being printable, with a good resolution. The characterization results showed that $3 \mathrm{Gel} / 4$ hydrogel crosslinked with $0.3 \mathrm{v} / \mathrm{v} \% \mathrm{GTA}$ presents optimal properties compared to the hydrogel with $2.5 \mathrm{Gel} 3$. In particular, the $3 \mathrm{Gel} 4$ 
hybrid composite hydrogel was able to maintain its print shape, to resist to the swelling and to degrade easily. Moreover, it shares a very good biocompatibility with the 2.5Gel3, and it could be used as a matrix for cell growth, for the development of in vitro tissues or also for wound dressing, allowing the host cells to gradually replace the hydrogel with a secreted matrix.

Author Contributions: Conceptualization, F.R. and M.I.; methodology, F.R. and B.P.; validation, M.S. and S.G.; formal analysis, B.P. and F.R.; investigation, B.P. and F.R.; resources, M.I.; data curation, F.R., B.P. and S.G.; writing—original draft preparation, M.S. and F.R.; writing—review and editing, M.S. and F.R.; supervision, F.R.; project administration, M.I.; funding acquisition, F.R., M.I. and S.G. All authors have read and agreed to the published version of the manuscript.

Funding: This research was funded by Health Sciences Department research fund, Università del Piemonte Orientale, grant number RIVinvernizzimRL16_BCRLrehab17_19. Department of Science and Technology Innovation, Università del Piemonte Orientale, grant number: RIVsabbatinimFAR17_ astrociti_19-21. The APC was funded by grant number RIVinvernizzimRL16_BCRLrehab17_19.

Institutional Review Board Statement: Not applicable.

Informed Consent Statement: Not applicable.

Data Availability Statement: The raw/processed data required to reproduce these findings cannot be shared at this time, as the data also form part of an ongoing study.

Acknowledgments: Authors thanks Marco De Andrea from Department of Public Health and Pediatric Sciences, University of Turin, 10126 Turin, Italy, for the kind gift of human primary fibroblast. The authors thank M.P. Fortunato for her precious help with the language.

Conflicts of Interest: The authors declare no conflict of interest. The funders had no role in the design of the study; in the collection, analyses or interpretation of data; in the writing of the manuscript; or in the decision to publish the results.

\section{References}

1. Rithe, S.S.; Kadam, P.G.; Mhaske, S.T. Preparation and analysis of novel hydrogels prepared from the blend of guar gum and chitosan: Cross-linked with glutaraldehyde. Adv. Mater. Sci. Eng. 2014, 2, 1-15.

2. El-Sherbiny, I.M.; Yacoub, M.H. Hydrogel scaffolds for tissue engineering: Progress and challenges. Glob. Cardiol. Sci. Pract. 2013, 2013, 38. [CrossRef] [PubMed]

3. Fan, L.; Tan, C.; Wang, L.; Pan, X.; Cao, M.; Wen, F.; Xie, W.; Nie, M. Preparation, characterization and the effect of carboxymethylated chitosan-cellulose derivatives hydrogels on wound healing. Appl. Polym. Sci. 2013, 128, 2789-2796. [CrossRef]

4. Narayanaswamy, R.; Torchilin, V.P. Hydrogels and their applications in targeted drug delivery. Molecules 2019, 24, 603. [CrossRef] [PubMed]

5. Dimatteo, R.; Darling, N.J.; Segura, T. In situ forming injectable hydrogels for drug delivery and wound repair. Adv. Drug Deliv. Rev. 2018, 127, 167-184. [CrossRef] [PubMed]

6. Naahidi, S.; Jafari, M.; Logan, M.; Wang, Y.; Yuan, Y.; Bae, H.; Dixon, B.; Chen, P. Biocompatibility of hydrogel-based scaffolds for tissue engineering applications. Biotechnol. Adv. 2017, 35, 530-544. [CrossRef]

7. Xiao, S.; Zhao, T.; Wang, J.; Wang, C.; Du, J.; Ying, L.; Lin, J.; Zhang, C.; Hu, W.; Wang, L. Gelatin methacrylate (GelMA)-based hydrogels for cell transplantation: An effective strategy for tissue engineering. Stem. Cell Rev. 2019, 15, 664-679. [CrossRef] [PubMed]

8. Mahdavi, S.S.; Abdekhodaie, M.J.; Mashayekhan, S.; Baradaran-Rafii, A.; Djalilian, A.R. Bioengineering Approaches for Corneal Regenerative Medicine. In Tissue Engineering and Regenerative Medicine; Springer: Berlin/Heidelberg, Germany, 2020; pp. 1-27. [CrossRef]

9. Smoak, M.M.; Mikos, A.G. Advances in biomaterials for skeletal muscle engineering and obstacles still to overcome. Mater. Today Bio 2020, 7, 100069. [CrossRef]

10. El-Kased, R.F.; Amer, R.I.; Attia, D.; Elmazar, M. Honey-based hydrogel: In vitro and comparative In vivo evaluation for burn wound healing. Sci. Rep. 2017, 7, 9692. [CrossRef]

11. Francesko, A.; Petkova, P.; Tzanov, T. Hydrogel dressings for advanced wound management. Curr. Med. Chem. 2018, 25, 5782-5797. [CrossRef]

12. Nour, S.; Baheiraei, N.; Imani, R.; Khodaei, M.; Alizadeh, A.; Rabiee, N.; Moazzeni, S.M. A review of accelerated wound healing approaches: Biomaterial-assisted tissue remodeling. J. Mater. Sci. Mater. 2019, 30, 120. [CrossRef] [PubMed] 
13. Shawan, M.M.A.K.; Islam, N.; Aziz, S.; Khatun, N.; Sarker, S.R.; Hossain, M.; Hossan, T.; Morshed, M.; Sarkar, M.; Shakil, M.S. Fabrication of Xanthan gum: Gelatin (Xnt: Gel) Hybrid Composite Hydrogels for Evaluating Skin Wound Healing Efficacy. Mod. Appl. Sci. 2019, 13. [CrossRef]

14. Wu, S.; Deng, L.; Hsia, H.; Xu, K.; He, Y.; Huang, Q.; Peng, Y.; Zhou, Z.; Peng, C. Evaluation of gelatin-hyaluronic acid composite hydrogels for accelerating wound healing. J. Biomater. Appl. 2017, 31, 1380-1390. [CrossRef] [PubMed]

15. Li, D.; Sun, H.; Jiang, L.; Zhang, K.; Liu, W.; Zhu, Y.; Fangteng, J.; Shi, C.; Zhao, L.; Sun, H. Enhanced biocompatibility of PLGA nanofibers with gelatin/nano-hydroxyapatite bone biomimetics incorporation. ACS Appl. Mater. Interfaces 2014, 6, $9402-9410$. [CrossRef] [PubMed]

16. Pezeshki-Modaress, M.; Zandi, M.; Mirzadeh, H. Fabrication of gelatin/chitosan nanofibrous scaffold: Process optimization and empirical modeling. Polym. Int. 2015, 64, 571-580. [CrossRef]

17. Camci-Unal, G.; Cuttica, D.; Annabi, N.; Demarchi, D.; Khademhosseini, A. Synthesis and characterization of hybrid hyaluronic acid-gelatin hydrogels. Biomacromolecules 2013, 14, 1085-1092. [CrossRef] [PubMed]

18. Petri, D.F. Xanthan gum: A versatile biopolymer for biomedical and technological applications. J. Appl. Polym. Sci. 2015, 132, 42035. [CrossRef]

19. Kumar, A.; Rao, K.M.; Han, S.S. Application of xanthan gum as polysaccharide in tissue engineering: A review. Carbohydr. Polym 2018, 180, 128-144. [CrossRef]

20. Karadağ, E.; Ödemiş, H.; Kundakçi, S.; Üzüm, Ö.B. Swelling characterization of acrylamide/zinc acrylate/xanthan gum/sepiolite hybrid hydrogels and its application in sorption of janus green b from aqueous solutions. Adv. Polym. Technol. 2016, 35, 248-259. [CrossRef]

21. Juris, S.; Mueller, A.; Smith, B.; Johnston, S.; Walker, R.; Kross, R. Biodegradable polysaccharide gels for skin scaffolds J. Biomater. Nanobiotechnol. 2011, 2, 216. [CrossRef]

22. Ratanavaraporn, J.; Rangkupan, R.; Jeeratawatchai, H.; Kanokpanont, S.; Damrongsakkul, S. Influences of physical and chemical crosslinking techniques on electrospun type A and B gelatin fiber mats. Int. J. Biol. Macromol. 2010, 47, 431-438. [CrossRef] [PubMed]

23. Lu, L.; Yuan, S.; Wang, J.; Shen, Y.; Deng, S.; Xie, L.; Yang, Q. The formation mechanism of hydrogels. Curr. Stem Cell Res. Ther. 2018, 13, 490-496. [CrossRef] [PubMed]

24. Yang, G.; Xiao, Z.; Long, H.; Ma, K.; Zhang, J.; Ren, X.; Zhang, J. Assessment of the characteristics and biocompatibility of gelatin sponge scaffolds prepared by various crosslinking methods. Sci. Rep. 2018, 8, 1616. [CrossRef] [PubMed]

25. Poursamar, S.A.; Lehner, A.N.; Azami, M.; Ebrahimi-Barough, S.; Samadikuchaksaraei, A.; Antunes, A.P.M. The effects of crosslinkers on physical, mechanical, and cytotoxic properties of gelatin sponge prepared via in-situ gas foaming method as a tissue engineering scaffold. Mater. Sci. Eng. C 2016, 63, 1-9. [CrossRef]

26. Sun, L.; Li, B.; Yao, D.; Song, W.; Hou, H. Effects of cross-linking on mechanical, biological properties and biodegradation behavior of Nile tilapia skin collagen sponge as a biomedical material. J. Mech. Behav. Biomed. Mater. 2018, 80, 51-58. [CrossRef] [PubMed]

27. Furuike, T.; Chaochai, T.; Okubo, T.; Mori, T.; Tamura, H. Fabrication of nonwoven fabrics consisting of gelatin nanofibers cross-linked by glutaraldehyde or N-acetyl-d-glucosamine by aqueous method. Int. J. Biol. Macromol. 2016, 93, 1530-1538. [CrossRef]

28. Mandrycky, C.; Wang, Z.; Kim, K.; Kim, D.-H. 3D bioprinting for engineering complex tissues. Biotechnol. Adv. 2016, 34, 422-434. [CrossRef]

29. Gungor-Ozkerim, P.S.; Inci, I.; Zhang, Y.S.; Khademhosseini, A.; Dokmeci, M.R. Bioinks for 3D bioprinting: An overview. Biomater. Sci. 2018, 6, 915-946. [CrossRef]

30. Dzobo, K.; Motaung, K.S.C.M.; Adesida, A. Recent trends in decellularized extracellular matrix bioinks for 3D printing: An updated review. Int. J. Mol. Sci. 2019, 20, 4628. [CrossRef]

31. Li, H.; Tan, C.; Li, L. Review of 3D printable hydrogels and constructs. Mater. Des. 2018, 159, 20-38. [CrossRef]

32. Lai, J.-Y. Biocompatibility of chemically cross-linked gelatin hydrogels for ophthalmic use. J. Mater. Sci. Mater. 2010, 21, 1899-1911. [CrossRef]

33. Afjoul, H.; Shamloo, A.; Kamali, A. Freeze-gelled alginate/gelatin scaffolds for wound healing applications: An in vitro, in vivo study. Mater. Sci. Eng. C 2020, 113, 110957. [CrossRef]

34. Etxabide, A.; Vairo, C.; Santos-Vizcaino, E.; Guerrero, P.; Pedraz, J.L.; Igartua, M.; de la Caba, K.; Hernandez, R.M. Ultra thin hydro-films based on lactose-crosslinked fish gelatin for wound healing applications. Int. J. Pharm. 2017, 530, 455-467. [CrossRef]

35. Hivechi, A.; Bahrami, S.H.; Siegel, R.A.; Milan, P.B.; Amoupour, M. In vitro and in vivo studies of biaxially electrospun poly (caprolactone)/gelatin nanofibers, reinforced with cellulose nanocrystals, for wound healing applications. Cellulose 2020, 27, 5179-5196. [CrossRef]

36. Shamloo, A.; Aghababaie, Z.; Afjoul, H.; Jami, M.; Bidgoli, M.R.; Vossoughi, M.; Ramazani, A.; Kamyabhesari, K. Fabrication and evaluation of Chitosan/Gelatin/PVA hydrogel incorporating Honey for wound healing applications: An In Vitro, In Vivo Study. Int. J. Pharm. 2020, 592, 120068. [CrossRef]

37. Additives, E.P.o.F.; Food, N.S.a.t.; Mortensen, A.; Aguilar, F.; Crebelli, R.; Di Domenico, A.; Frutos, M.J.; Galtier, P.; Gott, D.; Gundert-Remy, U.; et al. Re-evaluation of xanthan gum (E 415) as a food additive. EFSA J. 2017, 15, e04909. [CrossRef]

38. Lii, C.-Y.; Liaw, S.; Lai, V.-F.; Tomasik, P. Xanthan gum-gelatin complexes. Eur. Polym. J. 2002, 38, 1377-1381. [CrossRef] 
39. Correia, D.M.; Padrão, J.; Rodrigues, L.; Dourado, F.; Lanceros-Méndez, S.; Sencadas, V. Thermal and hydrolytic degradation of electrospun fish gelatin membranes. Polym. Test 2013, 32, 995-1000. [CrossRef]

40. Zhang, Y.; Venugopal, J.; Huang, Z.-M.; Lim, C.T.; Ramakrishna, S. Crosslinking of the electrospun gelatin nanofibers. Polymer 2006, 47, 2911-2917. [CrossRef]

41. Nilforoushzadeh, M.A.; Sisakht, M.M.; Amirkhani, M.A.; Seifalian, A.M.; Banafshe, H.R.; Verdi, J.; Nouradini, M. Engineered skin graft with stromal vascular fraction cells encapsulated in fibrin-collagen hydrogel: A clinical study for diabetic wound healing. J. Tissue Eng. Regen. Med. 2020, 14, 424-440. [CrossRef] [PubMed]

42. Wu, Y.; Heikal, L.; Ferns, G.; Ghezzi, P.; Nokhodchi, A.; Maniruzzaman, M. 3D bioprinting of novel biocompatible scaffolds for endothelial cell repair. Polymers 2019, 11, 1924. [CrossRef] [PubMed]

43. Farris, S.; Song, J.; Huang, Q. Alternative reaction mechanism for the cross-linking of gelatin with glutaraldehyde. J. Agric. Food Chem. 2010, 58, 998-1003. [CrossRef]

44. Schrieber, R.; Gareis, H. Gelatine Handbook: Theory and Industrial Practice; John Wiley \& Sons: Hoboken, NJ, USA, 2007.

45. Gorgieva, S.; Kokol, V. Collagen-vs. gelatine-based biomaterials and their biocompatibility: Review and perspectives. J. Biomater. Appl. 2011, 2, 17-52.

46. Bose, S.; Vahabzadeh, S.; Bandyopadhyay, A. Bone tissue engineering using 3D printing. Mater. Today 2013, 16, 496-504. [CrossRef]

47. An, J.; Teoh, J.E.M.; Suntornnond, R.; Chua, C.K. Design and 3D printing of scaffolds and tissues. Engineering 2015, 1, 261-268. [CrossRef] 